\title{
(2) OPEN ACCESS \\ Cardiac involvement in a child post COVID-19: a case from Lebanon
}

\author{
Tania H Abi Nassif, ${ }_{1}^{1}$ Karim N Daou, ${ }^{1}$ Theresia Tannoury, ${ }^{1,2}$ Marianne Majdalani ${ }^{1,3}$
}

${ }^{1}$ Department of Pediatrics and Adolescent Medicine, American University of Beirut Medical Center, Beirut, Lebanon ${ }^{2}$ Children Heart Center, Department of Pediatrics and Adolescent Medicine, American University of Beirut Medical Center, Beirut, Lebanon ${ }^{3}$ Pediatric Intensive Care Unit, Department of Pediatrics and Adolescent Medicine, American University of Beirut Medical Center, Beirut, Lebanon

\section{Correspondence to}

Dr Marianne Majdalani; mn40@aub.edu.lb

Accepted 27 April 2021

A Check for updates

(c) BMJ Publishing Group Limited 2021. Re-use permitted under CC BY-NC. No commercial re-use. See rights and permissions. Published by BMJ.

To cite: Abi Nassif TH, Daou KN, Tannoury T, et al. BMJ Case Rep

2021:14:e242084

doi:10.1136/bcr-2021.

242084

\section{SUMMARY}

We report on an 8-year-old boy, who presented to the emergency department at our institution with fever, generalised oedema and hypotension. Investigations revealed anaemia, thrombocytopenia in addition to elevated serum inflammatory markers, a negative COVID-19 PCR test and a positive COVID-19 lgG. His echocardiography was consistent with carditis in otherwise morphologically normal heart with depressed cardiac function, moderate-to-severe mitral valve regurgitation, moderate tricuspid regurgitation with an estimated right ventricular systolic pressure half systemic, trace aortic regurgitation, bilateral small pleural effusions, distended inferior vena cava and normal coronaries. He was started on inotropic support intravenous immunoglobulin and methylprednisolone, and was transferred to the paediatric intensive care unit. To the best of our knowledge, this was the first case of multisystem inflammatory syndrome in children encountered in Lebanon. The presentation and management were thoroughly described in this article aiming to share our experience and to contribute to the rapidly emerging literature on this syndrome.

\section{BACKGROUND}

The fast growing pandemic associated with SARS-CoV-2 has resulted in $>114$ million confirmed cases and $>2.5$ million global deaths. Early reports of symptoms and signs in children infected with COVID-19 indicated a favourable prognosis in paediatric population compared with adults as they presented mainly with a mild upper respiratory illness. ${ }^{2-4}$ This was mainly attributed to variances in immune responses to COVID-19. ${ }^{5}$ However, as of early May 2020, a national alert in the UK was prompted as investigators from South Thames Retrieval Service in London, UK published a report describing unprecedented cluster of eight severely ill children presenting in hyperinflammatory shock with multiorgan involvement. ${ }^{6}$ Particularly, reports suggest many have myocardial dysfunction ${ }^{7}$ and coronary artery involvement ${ }^{6}$ in addition to gastrointestinal and systemic symptoms. ${ }^{89}$ Clinical characteristics of these cases were comparable to the features of Kawasaki disease (KD), KD shock syndrome and toxic shock syndrome (TSS). ${ }^{6}$ Recently in Europe and parts of North America, series of children and adolescents with the same manifestations have required admission to intensive care units. ${ }^{10}$

This acute condition was labelled by the Royal College of Paediatrics and Child Health as paediatric multisystem inflammatory syndrome temporally associated with COVID-19. ${ }^{11}$ As more cases appeared worldwide, Centers for Disease Control and Prevention and the WHO issued an alert on this condition under the label of multisystem inflammatory syndrome in children (MISC). ${ }^{12} 13$

COVID-19 is uncommon in children, ${ }^{14}$ however, early diagnosis of MIS-C is essential for the management and the prevention of a severe inflammatory state. ${ }^{15}$ Following SARS-CoV-2 infection, the worldwide burden of the novel syndrome, MIS-C continues to escalate in the paediatric age group. Taking into consideration the fact that MIS-C can mimic other diseases including but not limited to $\mathrm{KD}$, this can make the diagnosis easily overlooked. The aim of our report is to describe one of the earliest cases of MIS-C in Lebanon, shedding light on the presentation and management with focus on cardiac involvement. We intend to contribute to the evolving literature on this syndrome hoping to reach an international consensus on the definition, presentation, management and outcomes of this syndrome.

\section{CASE PRESENTATION}

We describe the case of an 8-year-old boy with a history of contact with known COVID-19 cases with no documented COVID-19 infection and mild symptoms developed 1 month prior to presentation. He presented to our emergency department on 5 December 2020 with 1-week history of highgrade fever $\left(40^{\circ} \mathrm{C}\right)$ spiking every $5-6$ hours, poorly responding to antipyretics, chills, myalgia and severe headache.

He was evaluated on the third day of illness by his general practitioner and started on cefpodoxime with no response. He continued to mount high-grade fever with chills, new-onset abdominal distention, macular rash over his abdomen, oedema of the face and lower extremities and worsening of his abdominal distention (warranting a CT of the abdomen: dilated bowels, free fluid in the pelvis and mild splenomegaly). He progressively became somnolent and lethargic on the day of presentation.

Lab tests done 3 days prior to presentation revealed a positive serology test for COVID-19 (IgG: $79 \mathrm{~g} / \mathrm{L}$ ), creatinine of $1.08 \mathrm{mg} / \mathrm{dL}$ and blood urea nitrogen $40 \mathrm{mg} / \mathrm{dL}$ and thrombocytopenia.

On presentation, the patient was febrile $\left(38.3^{\circ} \mathrm{C}\right)$ and hypotensive (blood pressure $84 / 46 \mathrm{~mm} \mathrm{Hg}$ ). $\mathrm{He}$ had a heart rate of 122 beats/min, respiratory rate of 24 breaths/min and a saturation reaching 99\% on room air. On physical examination, he appeared tired and toxic and moderately dehydrated, had bilateral non-purulent bulbar (limbus-sparing) 


\begin{tabular}{|c|c|c|c|c|c|}
\hline & Ref. range & $05 / 12 / 20$ & $08 / 12 / 20$ & $13 / 12 / 20$ & $16 / 12 / 20$ \\
\hline Adjusted white blood cell & Ref. range: $4.5-13.5$ cells $\times 10^{9} \mathrm{~L}$ & $10.2 \times 10^{9}$ & $3.2 \times 10^{9}$ & $4.7 \times 10^{9}$ & $5 \times 10^{9}$ \\
\hline Neutrophils & Latest ref. range: $35 \%-65 \%$ & 75 & 70.7 & 75 & 74.7 \\
\hline Lymphocytes & Latest ref. range: $23 \%-53 \%$ & 18 & 24.1 & 24.5 & 25 \\
\hline Platelets & Latest ref. range: $150-400 \times 10^{9} / \mathrm{L}$ & $95.6 \times 10^{9}$ & $106 \times 10^{9}$ & $651 \times 10^{9}$ & $709 \times 10^{9}$ \\
\hline Carbon dioxide & Latest ref. range: $24-30 \mathrm{mmol} / \mathrm{L}$ & 20 & & & \\
\hline Bilirubin direct & Latest ref. range: $0.0-0.3 \mathrm{mg} / \mathrm{dL}$ & 0.8 & & 0.2 & 0.1 \\
\hline Lactate dehydrogenase & Latest ref. range: $110-265 \mathrm{IU} / \mathrm{L}$ & 232 & & & \\
\hline Albumin & Latest ref. range: $36-53 \mathrm{~g} / \mathrm{L}$ & 23 & 31 & 39 & \\
\hline Lactic acid (arterial) & Latest ref. range: $0.55-2.20 \mathrm{mmol} / \mathrm{L}$ & 2.92 & & & \\
\hline Procalcitonin & $\leq 0.05 \mathrm{ng} / \mathrm{mL}$ & 2.87 & 0.96 & & \\
\hline Alkaline phosphatase & Latest ref. range: $20-385 \mathrm{IU} / \mathrm{L}$ & 614 & & 342 & 251 \\
\hline Gamma-glutamyl transferase & Latest ref. range: $10-50 \mathrm{IU} / \mathrm{L}$ & $114(\mathrm{H})$ & & 501 & 392 \\
\hline Troponin T & Latest ref. range: $0.000-0.030 \mathrm{ng} / \mathrm{mL}$ & $0.083(\mathrm{H})$ & 0.06 & 0.05 & \\
\hline $\mathrm{C}$ reactive protein & Latest ref. range: $0.0-2.5 \mathrm{mg} / \mathrm{L}$ & $140.7(\mathrm{H})$ & 32.8 & 5.1 & 1.4 \\
\hline D-dimer & Latest ref. range: $\leq 255 \mathrm{ng} / \mathrm{mL}$ & $2319(\mathrm{H})$ & 3037 & 677 & 458 \\
\hline Haptoglobin & Latest ref. range: $0.30-2.00 \mathrm{~g} / \mathrm{L}$ & $2.04(H)$ & & & \\
\hline C3 complement & Latest ref. range: $0.90-1.80 \mathrm{~g} / \mathrm{L}$ & $0.42(L)$ & & & \\
\hline C4 complement & Latest ref. range: $0.10-0.40 \mathrm{~g} / \mathrm{L}$ & $<0.02(\mathrm{~L})$ & & & \\
\hline Cytomegalovirus IgM & Non-reactive $<0.85$ & Non-reactive & & & \\
\hline Cytomegalovirus IgG & Non-reactive $<6.0 \mathrm{AU} / \mathrm{mL}$ & $<6.0$ & & & \\
\hline
\end{tabular}

NT-pro-BNP, N-terminal pro-B-type natriuretic peptide; pro-BNP, pro-B-type natriuretic peptide.

conjunctivitis, cracked and dry lips, strawberry-red tongue with hyperemic oropharynx and a faint macular rash over the lower abdomen and suprapubic area, tachycardiac (110-130 beats/ min) with a grade II-III systolic murmur over the apical area, distended abdomen, with decreased bowel sounds and hepatosplenomegaly, scrotal and lower limb oedema. The examination was negative for meningeal signs and findings on lung auscultation.

Initial investigations revealed anaemia, thrombocytopenia, acute liver and kidney injuries, hypoalbuminaemia, elevated inflammatory markers as well as troponin $\mathrm{T}$ and pro-B-type natriuretic peptide (pro-BNP; table 1). Qualitative test for COVID-19 immunoglobulins (Ig) was negative for IgM and positive for IgG. COVID-19 real time-PCR from nasopharyngeal swab was negative.

Bedside echocardiography findings were consistent with carditis with otherwise morphologically normal heart. They revealed mildly depressed left ventricle systolic function with estimated ejection fraction (EF) of 50\%-53\%. Moderate-tosevere mitral valve regurgitation was seen with suspicion of mitral valve anterior leaflet prolapse versus a ruptured chordae as well as trace aortic regurgitation. There also was a moderate tricuspid regurgitation with the estimated right ventricular systolic pressure being the half systemic pressure. A bilateral small pleural effusion and a tiny pericardial effusion were noted.
The mitral valve was of normal morphology and leaflets but with an eccentric regurgitation that was moderate to severe with double jets. There was suspicion for a probability of ruptured chordae of the anterior mitral leaflet. The tricuspid valve was moderately regurgitant with a jet pointing towards the coronary sinus causing dilation of the coronary sinus ostium. The proximal visualised part of the coronaries was normal and showed no dilatation.

Noninvasive respiratory support (face mask oxygen $3 \mathrm{~L} / \mathrm{min}$ ) was initiated, and the patient received fluid resuscitationand was started on vasopressors (epinephrine and milrinone) for cardiac support. Broad-spectrum antibiotics were empirically initiated (intravenous ceftriaxone and vancomycin: given the prevalence of methicillin-resistant Staphylococcus aureus in the community) while awaiting culture results and serologies.

Given his prolonged fever, multiorgan dysfunction, significantly elevated inflammatory markers, lack of alternative diagnosis and prior SARS-CoV-2 exposure of the child was suspected to have MIS-C as he fulfilled the diagnostic criteria ${ }^{13}$ and he was admitted to the paediatric intensive care unit (PICU) for cardiac support and close monitoring. He initially received two doses of intravenous immunoglobulin $(1 \mathrm{~g} / \mathrm{kg}$ each) 10 hours apart. $\mathrm{He}$ was started on methylprednisolone $(1 \mathrm{mg} / \mathrm{kg} /$ dose intravenously every 12 hours). 


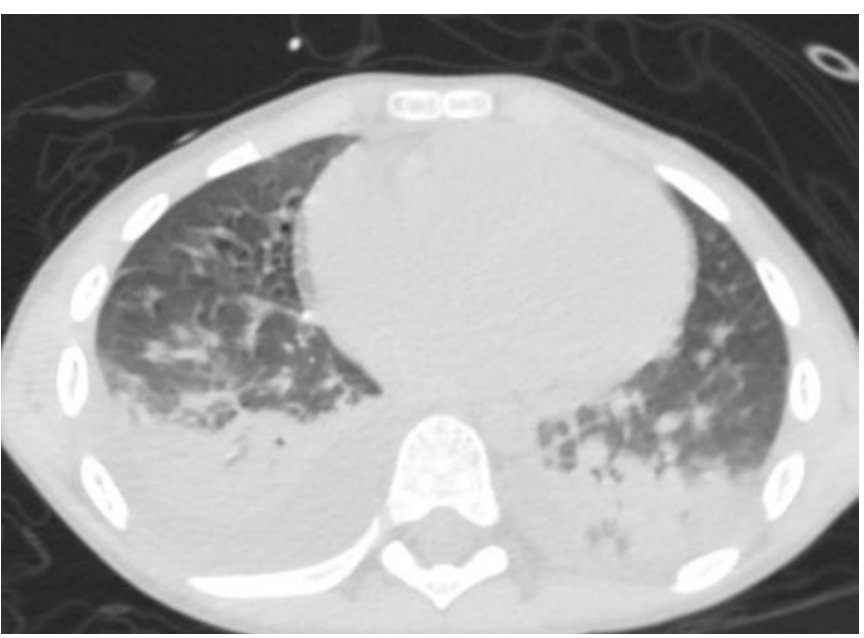

Figure 1 Chest and abdominal CT on second day of admission.

On the second day of admission, he became tachypneic. CT chest was done and showed typical MIS-C radiographic findings: bibasilar subsegmental consolidations with small pleural effusions, basilar septal lines and subpleural consolidations and ground-glass abnormalities in the right middle lobe (figure 1).

As his platelet count increased $>100 \times 10^{9} / \mathrm{L}$, low-dose aspirin $(81 \mathrm{mg})$ was initiated. Although his EF was not severely affected, the patient was started on enoxaparin for venous thromboembolism prophylaxis due to his marked $\mathrm{D}$-dimer elevation on the third day of hospitalisation $(3037 \mathrm{ng} / \mathrm{mL})$.

On the fifth day of admission, the patient started to have bradycardia on telemetry with a nadir heart rate of 40 beats/ min and premature atrial contractions (blocked with aberrancy) which resolved spontaneously after 2 days.

\section{OUTCOME AND FOLLOW-UP}

His clinical condition improved as well as his laboratory markings and his echocardiographic findings with normalisation of his EF along with significant improvement in his mitral regurgitation (figure 2), thus transferred to the regular floor after 6 days of intensive care.

On the seventh day, he developed typical Kawasaki-like desquamating rash on his fingers.

The patient was successfully discharged home on the ninth day of admission on oral steroids, fursemide, captopril and lowdose acetysalicylic acid (aspirin).

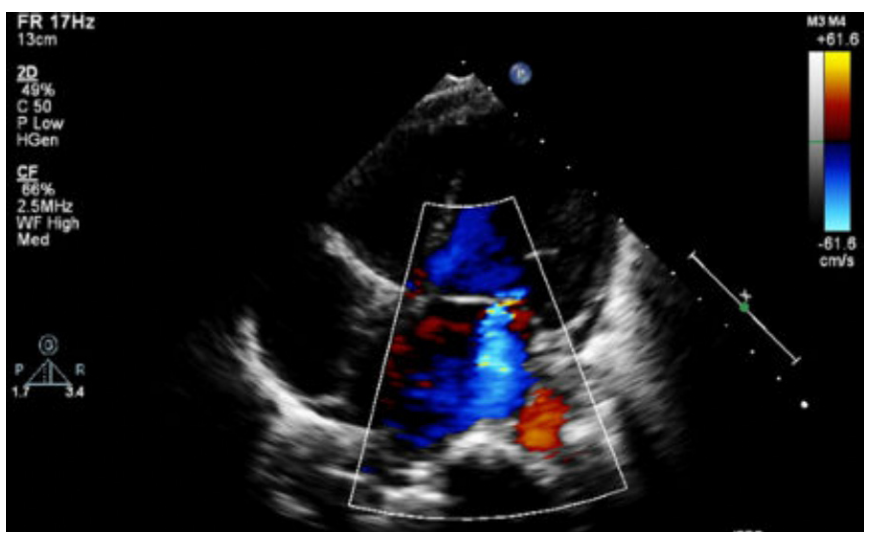

Figure 2 Echocardiogram: moderate-to-severe mitral valve regurgitation.
At 1 and 2 months of follow-up, the patient was completely asymptomatic. Lab results were noteworthy for thrombocytosis. Steroids were weaned over 3 weeks and aspirin was stopped after 3 weeks when platelets were back to normal $\left(200 \times 10^{9} / \mathrm{L}\right)$. Furosemide was stopped at 2 months. His cardiac examination revealed considerably improved function without any conduction abnormalities (table 2).

\section{DISCUSSION}

\section{Differential diagnosis}

Differentiating MIS-C from conditions such as KD, sepsis and TSS can pause a challenge to clinicians owing to the fact that MIS-C involves all organ systems and manifests with extensive laboratory derangements. KD is an acute, self-limited vasculopathy predominantly affecting children $<5$ years of age. It leads to vasculitis in medium-sized arteries with systemic inflammation. Up to $25 \%$ of untreated cases may end up with acquired coronary artery aneurysms. Children with KD present with prolonged high-grade fever and mucocutaneous changes. Classical KD is diagnosed based on the clinical criteria. Children who have prolonged fever without meeting all the principal clinical criteria have atypical KD. The mainstays of treatment of KD are intravenous immunoglobulins and acetylsalicylic acid. ${ }^{16}$ Despite the remarkable phenotypic overlap between MIS-C and KD, there are variations in the age groups affected, cardiac manifestations and inflammatory markers. SARS-CoV-2 exposure history remains the pertinent feature of MIS-C diagnosis. ${ }^{17}$ Sepsis is defined as a widespread inflammatory response associated with a suspected or proven infection. Further cardiovascular dysfunction may evolve leading to septic shock. ${ }^{18}$ The underlying pathogen may be bacterial, viral, fungal or parasitic. Children presenting with signs of sepsis or septic shock need to be rapidly resuscitated with fluids and empirically covered with broadspectrum antibiotics until culture results are out. ${ }^{19}$ It is worthy to note that MIS-C can manifest with signs of septic shock, although coronary artery involvement, valvulitis and left ventricular dysfunction are unique to MIS-C. ${ }^{20}$ S. aureus and Streptococcus pyogenes are bacteria capable of producing exotoxins which act as superantigens that stimulate T-cells and cause a massive cytokine release leading to TSS. ${ }^{21}$ The patient presents with rapid onset of fever, hypotension, rash, mucosal membranes involvement and multiorgan dysfunction. ${ }^{22}$ The mainstays of treatment of TSS are fluid resuscitation and antibiotics. ${ }^{23}$

\section{Multisystem inflammatory syndrome in children}

Multisystem inflammatory syndrome is a novel disease in paediatrics linked to SARS-CoV-2 that has high mortality and required management in PICU. According to a review of previous observational studies, the main manifestations were fever, myalgia, rash, dyspnoea, conjunctivitis, gastrointestinal symptoms, depressed mental status and evidence of organ failure with elevated inflammatory markers and evidence of COVID-19 infection or recent contact with the patient with COVID-19, with no other explanation of such presentation. ${ }^{24}$ All of these signs and symptoms were observed in our patient on admission to PICU.

\section{Cardiac involvement in MIS-C}

Noticeably, since the beginning of the pandemic, reports of cardiac sequalae in paediatric patients presenting with MIS-C have been rapidly growing. ${ }^{25}{ }^{26}$ In our case, cardiac dysfunction was the most pronounced organ involvement encountered. The initial presentation of our patient was a cardiogenic shock secondary to left ventricular dysfunction that did not improve 


\begin{tabular}{|c|c|}
\hline Echocardiography & Findings \\
\hline Admission & $\begin{array}{l}\text { Depressed left ventricular systolic function, estimated EF } 50 \%-53 \% \text {, moderate-to-severe MR, suspicion of anterior MV leaflet tip prolapse versus chordae } \\
\text { rupture } \\
\text { Trace AR, moderate TR, RVSP half systemic. Bilateral pleural effusions, small pericardial effusion } \\
\text { Right and left ventricles mildly dilated } \\
\text { Coronaries show no dilatation or aneurysm }\end{array}$ \\
\hline Discharge & $\begin{array}{l}\text { Improved LV systolic function, estimated EF } 60 \%-65 \% \text {, moderate MR with prolapsed anterior leaflet, trace AR, moderate TR, normal LV longitudinal strain } \\
-27 \% \text {, normal LV and RV size } \\
\text { No pericardial or pleural effusion }\end{array}$ \\
\hline 1-month follow-up & $\begin{array}{l}\text { Improved LV systolic function, estimated EF } 60 \%-65 \% \text {, mild MR, trivial TR, PR and AR } \\
\text { Normal LV longitudinal strain }-24 \% \\
\text { No pericardial or pleural effusion }\end{array}$ \\
\hline
\end{tabular}

$A R$, aortic regurgitation; EF, ejection fraction; LV, left ventricle; MR, mitral regurgitation; MV, mitral valve; RV, right ventricle; RVSP, right ventricular systolic pressure; TR, tricuspid regurgitation.

despite fluid boluses, which necessitated the early initiation of inotropic support. The earliest literature description of MIS-C or 'Hyperinflammatory shock in children' by Riphagen et al reported eight patients presenting with vasoplegic shock that was refractory to volume resuscitation and required norepinephrine and milrinone for haemodynamic sustenance. Nearly all children had myocardial involvement and this was evidenced by elevated cardiac enzymes and echocardiographic findings ranging from ventricular dysfunction to coronary dilatation. ${ }^{6}$

\section{Echocardiograpic findings}

Myocarditis

The predominant cardiac finding in patients with MIS-C is acute myocardial dysfunction. ${ }^{27}$ Myocarditis is an inflammation of the myocardium. It is diagnosed based on histological, immunological, immunohistochemical and molecular criteria. ${ }^{28}$ It results in dysfunction of the cardiac muscle and its conductivity compromising the cardiac contractility and consequently cardiac output. ${ }^{29}$ This was evident in our patient, who presented with left ventricular dysfunction and a mildly depressed cardiac function $(\mathrm{EF}=50 \%)$. The common cardiac manifestation in MIS-C is depression of the EF. Reports from case series in France and Switzerland of 35 children admitted to intensive care unit, revealed depressed left ventricle (LV) function in all with $\mathrm{EF}<30 \%$ in one-third of them; $80 \%$ of whom required inotropic support. ${ }^{25}$ Larger case series from the UK involving 58 hospitalised children fulfilling MIS-C criteria showed that 50\% developed shock, that was associated with evidence of LV dysfunction on echocardiography and elevated troponin and pro-BNP. ${ }^{30}$ The patient in our report, had a substantially high pro-BNP (N-terminal pro-B-type natriuretic peptide (NT-pro-BNP)) of $13369 \mathrm{pg} / \mathrm{mL}$ that peaked to $21481 \mathrm{pg} / \mathrm{mL}$ on the second day and an elevated troponin $\mathrm{T}$ of $0.083 \mathrm{ng} / \mathrm{mL}$ (range: $0.000-0.030 \mathrm{ng} / \mathrm{mL}$ ) on presentation. In one of the largest case series published to date, Valverde et $a l^{31}$ recruited $\mathrm{n}=286$ children, the most common cardiovascular sequalae were shock, arrhythmias, pericardial effusion and coronary artery dilatation and over half of the patients had decreased LV EF. Although the mechanism of cardiac involvement has been explained in adults with COVID-19 acute infection, the temporal difference between the actual infection and onset of cardiac manifestations in children is suggestive of a rather postinfectious immunological response that does not often spare the myocardium in predisposed subjects. ${ }^{32}$

Perhaps the most striking finding in the patient's echocardiography was the multiple valvular involvements he presented with, namely, the moderate-to-severe mitral regurgitation, moderate tricuspid regurgitation and trace aortic insufficiency. The mitral valve was remarkably regurgitant with two significant eccentric jets (figure 2). In one study in UK by Theocharis et al, ${ }^{33}$ echocardiography of 20 patients with MIS-C was positive for valvular regurgitations in $75 \%$.

\section{Arrhythmia}

To date, sinus node dysfunction associated with COVID-19 has not been widely reported in paediatrics, however, there are several case reports describing bradycardia in adult population. Peigh $e a^{3 l^{34}}$ reported two cases of COVID-19-associated pathological sinus node dysfunction mainly sinus bradycardia. Although the mechanism for COVID-19-associated myocardial conduction abnormalities is currently speculative from previous coronavirus epidemics, it is possible that myocardial inflammation or direct viral infiltration via ACE2 affects myocardial conduction, leading to an impaired chronotropic response and progressive conduction system disease. ${ }^{34} 35$

Arrhythmia has been described in patients with MIS-C. Children may present with first-degree heart block and it has been reported more in patients with depressed left ventricular systolic function. ST-segment changes, QT prolongation and T-wave abnormalities have been documented in patients with MIS-C on electrocardiograms. ${ }^{36}$

\section{Learning points}

The emergence of the multisystem inflammatory syndrome in children (MIS-C) cases in Lebanon, as in the rest of the world, is only at its advent.

- This novel syndrome is highly reflective of a delayed hyperinflammatory immune response to SARS-CoV-2 infection in the paediatric age group from early neonatal age through late adolescence. Establishing a diagnosis can be somehow challenging due to similarities this condition shares with Kawasaki disease and toxic shock syndrome. It has been recognised to be a separate entity with its unique presentation and pathophysiology.

- Although the published literature has reported that most children with MIS-C show recovery, both short-term and longterm outcomes are yet to be learnt.

- It is warranted that all paediatric healthcare providers have a high degree of suspicion and low threshold for MIS-C diagnosis, management and follow-up.

- More studies are encouraged to elucidate the exact pathophysiology of this entity to provide evidence-based management tools and to unravel its prognostic outcomes. 
Twitter Theresia Tannoury @theresia tannoury

Contributors MM, THAN, KND and TT: wrote the report; THAN and KND: conducted the literature search; MM: supervised and proof-read.

Funding The authors have not declared a specific grant for this research from any funding agency in the public, commercial or not-for-profit sectors.

Competing interests None declared.

Patient consent for publication Obtained.

Provenance and peer review Not commissioned; externally peer reviewed.

Open access This is an open access article distributed in accordance with the Creative Commons Attribution Non Commercial (CC BY-NC 4.0) license, which permits others to distribute, remix, adapt, build upon this work non-commercially, and license their derivative works on different terms, provided the original work is properly cited and the use is non-commercial. See: http://creativecommons.org/ licenses/by-nc/4.0/.

\section{REFERENCES}

1 Johns Hopkins Coronavirus Resource Center. COVID-19 Map - Johns Hopkins Coronavirus Resource Center, 2021. Available: https://coronavirus.jhu.edu/map.html [Accessed 21 Mar 2021].

2 Rodriguez-Morales AJ, Cardona-Ospina JA, Gutiérrez-Ocampo E, et al. Clinical, laboratory and imaging features of COVID-19: a systematic review and meta-analysis. Travel Med Infect Dis 2020;34:101623.

3 Castagnoli R, Votto M, Licari A, et al. Severe acute respiratory syndrome coronavirus 2 (SARS-CoV-2) infection in children and adolescents: a systematic review. JAMA Pediatr 2020;174:882-9.

4 Hong H, Wang Y, Chung H-T, et al. Clinical characteristics of novel coronavirus disease 2019 (COVID-19) in newborns, infants and children. Pediatr Neonatol 2020;61:131-2.

5 Molloy EJ, Bearer CF. COVID-19 in children and altered inflammatory responses. Pediatr Res 2020;88:340-1.

6 Riphagen S, Gomez X, Gonzalez-Martinez C, et al. Hyperinflammatory shock in children during COVID-19 pandemic. The Lancet 2020;395:1607-8.

7 Bertoncelli D, Guidarini M, Della Greca A, et al. COVID19: potential cardiovascular issues in pediatric patients. Acta Biomed 2020;91:177-83.

8 Wei M, Yuan J, Liu Y, et al. Novel coronavirus infection in hospitalized infants under 1 year of age in China. JAMA 2020;323:1313-4.

9 Zimmermann P, Curtis N. Coronavirus infections in children including COVID-19: an overview of the epidemiology, clinical features, diagnosis, treatment and prevention options in children. Pediatr Infect Dis J 2020;39:355-68.

10 WHO. Multisystem inflammatory syndrome in children and adolescents temporally related to COVID-19. Available: https://www.who.int/news-room/commentaries/ detail/multisystem-inflammatory-syndrome-in-children-and-adolescents-with-covid-19 [Accessed 21 Mar 2021].

11 rcpch.ac.uk. Paediatric multisystem inflammatory syndrome temporally associated with COVID-19 (PIMS) - guidance for clinicians. Available: https://www.rcpch.ac.uk/ resources/paediatric-multisystem-inflammatory-syndrome-temporally-associatedcovid-19-pims-guidance [Accessed 21 Mar 2021].

12 World Health Organization. Multisystem inflammatory syndrome in children and adolescents with COVID-19, 2020. Available: https://www.who.int/publicationsdetail/multisysteminflammatorysyndrome- in-children-and-adolescents-withcovid-19 [Accessed 20 Dec 2020].

13 Emergency.cdc.gov. HAN Archive - 00432 | Health Alert Network (HAN), 2021. Available: https://emergency.cdc.gov/han/2020/han00432.asp [Accessed 21 Mar 2021].

14 RCPCH. Paediatric multisystem inflammatory syndrome temporally associated with COVID-19 (PIMS) - guidance for clinicians. Available: https://www.rcpch.ac.uk/ resources/paediatric-multisystem-inflammatory-syndrome-temporally-associatedcovid-19-pims-guidance [Accessed 20 Dec 2020].

15 Yasuhara J, Kuno T, Takagi H, et al. Clinical characteristics of COVID-19 in children: a systematic review. Pediatr Pulmonol 2020;55:2565-75.

16 McCrindle BW, Rowley AH, Newburger JW, et al. Diagnosis, treatment, and long-term management of Kawasaki disease: a scientific statement for health professionals from the American heart association. Circulation 2017;135:e927-99.

17 Lee PY, Day-Lewis M, Henderson LA, et al. Distinct clinical and immunological features of SARS-CoV-2-induced multisystem inflammatory syndrome in children. Journal of Clinical Investigation 2020;130:5942-50.

18 Goldstein B, Giroir B, Randolph A, et al. International pediatric sepsis consensus conference: definitions for sepsis and organ dysfunction in pediatrics. Pediatr Crit Care Med 2005;6:2-8.

19 Weiss SL, Peters MJ, Alhazzani W, et al. Surviving sepsis campaign international guidelines for the management of septic shock and sepsis-associated organ dysfunction in children. Intensive Care Med 2020;46:10-67.

20 Lin Y-J, Cheng M-C, Lo M-H, et al. Early differentiation of Kawasaki disease shock syndrome and toxic shock syndrome in a pediatric intensive care unit. Pediatr Infect Dis J 2015:34:1163-7.

21 Li Y, Luo C, Li W, et al. Structure-Based preliminary analysis of immunity and virulence of SARS coronavirus. Viral Immunol 2004;17:528-34.

22 Chuang Y-Y, Huang Y-C, Lin T-Y. Toxic shock syndrome in children: epidemiology, pathogenesis, and management. Paediatr Drugs 2005;7:11-25.

23 Parks T, Wilson C, Curtis N, et al. Polyspecific intravenous immunoglobulin in clindamycin-treated patients with streptococcal toxic shock syndrome: a systematic review and meta-analysis. Clin Infect Dis 2018;67:1434-6.

24 Ahmed M, Advani S, Moreira A, et al. Multisystem inflammatory syndrome in children: a systematic review. EClinicalMedicine 2020;26:100527.

25 Belhadjer Z, Méot M, Bajolle F, et al. Acute heart failure in multisystem inflammatory syndrome in children in the context of global SARS-CoV-2 pandemic. Circulation 2020;142:429-36.

26 Driggin E, Madhavan MV, Bikdeli B, et al. Cardiovascular considerations for patients, health care workers, and health systems during the COVID-19 pandemic. J Am Coll Cardiol 2020;75:2352-71.

27 Blondiaux E, Parisot P, Redheuil A, et al. Cardiac MRI in children with multisystem inflammatory syndrome associated with COVID-19. Radiology 2020;297:E283-8.

28 Caforio ALP, Pankuweit S, Arbustini E, et al. Current state of knowledge on aetiology, diagnosis, management, and therapy of myocarditis: a position statement of the European Society of cardiology Working group on myocardial and pericardial diseases. Eur Heart J 2013;34:2636-48.

29 Beșler MS, Arslan H. Acute myocarditis associated with COVID-19 infection. Am J Emerg Med 2020;38:2489.e1-2489.e2

30 Whittaker E, Bamford A, Kenny J, et al. Clinical characteristics of 58 children with a pediatric inflammatory multisystem syndrome temporally associated with SARS CoV-2. JAMA 2020;324:259-69.

31 Valverde I, Singh Y, Sanchez-de-Toledo J, et al. Acute cardiovascular manifestations in 286 children with multisystem inflammatory syndrome associated with COVID-19 infection in Europe. Circulation 2021;143:21-32.

32 Sperotto F, Friedman KG, Son MBF, et al. Cardiac manifestations in SARS-CoV-2associated multisystem inflammatory syndrome in children: a comprehensive review and proposed clinical approach. Eur J Pediatr 2021;180:307-22.

33 Theocharis P, Wong J, Pushparajah K, et al. Multimodality cardiac evaluation in children and young adults with multisystem inflammation associated with COVID-19. Eur Heart J Cardiovasc Imaging 2020. doi:10.1093/ehjci/jeaa212. [Epub ahead of print: 07 Aug 2020].

34 Peigh G, Leya MV, Baman JR, et al. Novel coronavirus 19 (COVID-19) associated sinus node dysfunction: a case series. Eur Heart J Case Rep 2020;4:1-6.

35 Kochi AN, Tagliari AP, Forleo GB, et al. Cardiac and arrhythmic complications in patients with COVID-19. J Cardiovasc Electrophysio/ 2020;31:1003-8.

36 Blondiaux E, Parisot P, Redheuil A, et al. Cardiac MRI in children with multisystem inflammatory syndrome associated with COVID-19. Radiology 2020;297:E283-8. 
Copyright 2021 BMJ Publishing Group. All rights reserved. For permission to reuse any of this content visit https://www.bmj.com/company/products-services/rights-and-licensing/permissions/

BMJ Case Report Fellows may re-use this article for personal use and teaching without any further permission.

Become a Fellow of BMJ Case Reports today and you can:

- Submit as many cases as you like

- Enjoy fast sympathetic peer review and rapid publication of accepted articles

- Access all the published articles

- Re-use any of the published material for personal use and teaching without further permission

Customer Service

If you have any further queries about your subscription, please contact our customer services team on +44 (0) 2071111105 or via email at support@bmj.com.

Visit casereports.bmj.com for more articles like this and to become a Fellow 